\title{
Os programas universitários para pessoas idosas (UnATIs): um estudo de representação social
}

\section{University programs for elderly people (UnATI): a study of social representation}

\section{Denize Cristina de Oliveira*}

Universidade do Estado do Rio de Janeiro - UERJ, Rio de Janeiro, Rio de Janeiro, Brasil

\section{Adriana Sancho Simoneau**}

Universidade do Estado do Rio de Janeiro - UERJ, Rio de Janeiro, Rio de Janeiro, Brasil

\begin{abstract}
RESUMO
Este estudo tem como objetivo conhecer, analisar e comparar as representações sociais construídas por pessoas idosas que participam de duas universidades latino-americanas, sendo uma da Costa Rica (PIAM-UCR) e outra do Brasil (UnATI-UERJ), sobre os programas universitários para a Terceira Idade (UnATIS). Como referencial teórico-metodológico optou-se pela Teoria das Representações Sociais (TRS). Realizou-se como técnica a entrevista em profundidade $(\mathrm{N}=14)$. Os dados foram submetidos à análise estatística (SPSS 17) e análise de conteúdo (Atlas ti5). As representações sociais sobre as UnATIs apreendidas neste trabalho encontram-se ancoradas em dois conceitos: a universidade como instituição de ensino superior e; a tríade pessoa idosa-velhice-envelhecimento. Destaca-se um posicionamento positivo na representação da UnATI como um lugar para compartilhar com pessoas da mesma idade num espaço de relacionamento social próprio para este grupo etário e como um espaço para adquirir e renovar conhecimentos na velhice.
\end{abstract}

Palavras-chave: Programa Universitário para a Terceira Idade, Representações Sociais, Pessoa Idosa.

\begin{abstract}
This study aims to evaluate, analyze and compare the social representations built by elderly participants in two Latin American universities programs, one of Costa Rica (PIAM-UCR) and one from Brazil (UnATI-UERJ). Its chosen theoretical and methodological frame of reference was Social Representations Theory. We performed the technique as in-depth interviews $(\mathrm{N}=14)$. Data were subjected to statistical analysis (SPSS 17) and content analysis (Atlas ti5). Social representations of UnATIs run seized in this work are rooted in two concepts: the university as an institution of higher education, the triad - old people-elder-aging. It stands out a positive position in the representation of UnATI as a place to share with people the same age within a social relationship itself for this age group and as a place to acquire and renew skills in old age.
\end{abstract}


Keywords: University Program for the Elderly, Social Representations, Elderly.

\section{I ntrodução}

O acelerado crescimento demográfico como fenômeno mundial mobilizou instâncias políticas, econômicas, educativas e culturais e colocou a necessidade de repensar os conceitos e as ações dirigidas às demandas e necessidades da população idosa. Na segunda metade do século XIX, na América Latina, o percentual de pessoas cuja vida se prolongava à etapa da velhice era menor do que aquele observado hoje em dia. Na atualidade, um grande contingente de pessoas consegue atingir esta etapa de vida, não apenas em função dos avanços da medicina, da psicologia, da saúde pública e do setor econômico, mas, também, como consequência do declive nas taxas de natalidade e mortalidade, acompanhadas do incremento na esperança de vida ao nascer.

Dessa forma, a formulação de políticas voltadas às necessidades deste amplo grupo permitiu que o problema do envelhecimento e da velhice saíssem do âmbito privado para a esfera pública e a mídia. Essa publicização tornou visível que o envelhecimento não é um problema dos idosos, e sim repetição de todas as pessoas que estão vivendo e envelhecendo cotidianamente.

Neste contexto, em 1973 o professor Pierre Vellas, preocupado em oferecer um espaço às pessoas idosas, criou na França o primeiro programa universitário voltado para a população idosa (DUFRESNE, 1996). Tal evento desencadeou um forte movimento em todo o mundo, que se ampliou para diversos países. Passaram a desenvolver-se espaços com diversas denominações, universidades, programas, escolas abertas ou projetos - voltados para a terceira idade, (CACHIONI, 2008). Aspecto que não foi diferente na Costa Rica e no Brasil.

No Brasil, especificamente na Universidade do Estado do Rio de J aneiro, com a visão futurista do Dr. Américo Piquet Carneiro, criouse em 1992, a Universidade Aberta para a Terceira Idade (UnATIUERJ), que entrou em vigor em 1993 (VERAS; CALDAS, 2004).

Pelo lado da Costa Rica, foi o Dr. Alfonso Trejos Willis, professor da Universidade da Costa Rica, quem impulsionou a criação de um programa voltado à população idosa. Em 1986 foram abertas vagas em disciplinas regulares da universidade para estudantes idosos do Programa Integral para Pessoas Idosas (PIAM-UCR), caracterizandose como um programa pioneiro no país (PIAM, 2008).

Ambos os espaços, a UnATI-UERJ e o PIAM-UCR, têm entre seus objetivos brindar uma alternativa diferente para que as pessoas idosas utilizem seu tempo livre de maneira cultural, social e 
esportiva. Além disso, visam a integração das pessoas idosas com diferentes gerações, assim como a atualização e aquisição de novos conhecimentos, possibilitando a participação integral, a elevação da autoestima e, como consequência, contribuir para uma melhora significativa da qualidade de vida desse grupo populacional.

Depois de uma revisão bibliográfica realizada sobre os trabalhos que abordam o tema do envelhecimento e da velhice, a partir da teoria das representações sociais, concorda-se com Frutuoso (1999) no sentido de que as pesquisas sobre a temática ainda são poucas, e no que se refere concretamente ao estudo da representação de espaços universitários destinados às pessoas idosas, eles são ainda mais limitados.

Dentro desse marco de referência, a presente pesquisa teve como objetivo principal conhecer, analisar e comparar as representações sociais construídas por pessoas idosas que participam de duas universidades latino-americanas, sendo uma da Costa Rica (PIAM) e outra do Brasil (UnATI-UERJ), sobre as UnATIs.

\section{Referencial teórico-metodológico}

Definiu-se como orientação teórico-metodológica a Teoria das Representações Sociais (TRS) - no contexto da Psicologia Social, pautada nas abordagens processual e estrutural como complementar. A TRS permite compreender a construção social da realidade considerando como ponto de partida os fenômenos psicossociais inseridos nas condições históricas e culturais específicas (JODELET, 2001; SÁ, 1998).

A coleta de dados ocorreu no período de 2007 a 2009, em dois cenários: o Programa Integral para a Pessoa Idosa, da Universidade de Costa Rica (PIAM-UCR), e a Universidade Aberta da Terceira Idade, da Universidade do Estado do Rio de Janeiro (UnATI-UERJ). As características desses espaços resultam propícias e homogêneas para a conformação e manutenção do fenômeno estudado.

Optou-se pela utilização da técnica de entrevista em profundidade, aplicada individualmente. Todas as entrevistas foram gravadas digitalmente e têm uma média de duração de 43 minutos na UnATIUERJ e 50 minutos no PIAM-UCR. A entrevista foi realizada com o auxílio de um roteiro estruturado. Com a finalidade de proteger a identidade dos sujeitos, foram identificados por letra e ordem numérica, contemplando a questão de gênero. Ex: Sr01, Sra02, Sr03...

Para a seleção das pessoas entrevistadas foram utilizados os seguintes critérios de inclusão: aceite em participar, estar devidamente inscrito nas disciplinas do programa e ter uma idade igual ou superior a 60 anos. Com o objetivo de garantir a 
familiaridade dos sujeitos com o objeto. Com o objetivo de garantir a familiaridade dos sujeitos com o objeto, optou-se por pessoas idosas que tivessem participado do programa por um tempo igual ou superior a dez anos.

Os dados foram submetidos às seguintes análises: analise estatística descritiva - calculo das medidas de tendência central (software SPSS 17) e de conteúdo temática ( software Atlas ti 5). Essa última análise pode ser definida como um conjunto de técnicas de análise que permite dar conta das comunicações através de procedimentos sistemáticos e objetivos de descrição do conteúdo das mensagens (BARDIN, 2009).

Nesta pesquisa foram obedecidos os princípios éticos e morais tanto com as instituições que autorizaram a realização da pesquisa quanto com os sujeitos que cederam participar após leitura e assinatura do Termo de Consentimento Livre e Esclarecido.

\section{Resultados e discussão}

A análise ATLAS Ti do corpus da pesquisa formado pelas entrevistas em profundidade das 14 pessoas idosas participantes ( 7 em cada programa), nos dois lócus escolhidos, resultou em 3006 unidades de registro, sendo $1410(46,90 \%)$ do PIAM-UCR e $1596(53,09 \%)$ da UNATI-UERJ, associadas a 68 unidades de significação revelando homogeneidade quantitativa nos dois campos estudados. A agregação dessas unidades resultou em 11 categorias semânticas, conforme pode ser observado no Quadro 1. 


\begin{tabular}{|c|c|c|c|c|c|c|c|}
\hline COD & Categorias & 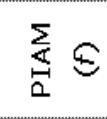 & 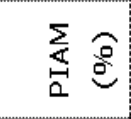 & $\underset{\Xi}{\leftrightarrows} \Phi$ & 志 & $\begin{array}{l}\text { Total } \\
(\mathrm{F})\end{array}$ & $\begin{array}{l}\text { Total } \\
(\%)\end{array}$ \\
\hline 001 & $\begin{array}{l}\text { Experiência educativa previa ao } \\
\text { ingresso ao Programa }\end{array}$ & 366 & 25,96 & 394 & 24,69 & 760 & 25,28 \\
\hline 005 & Inscriçãoe Motivos no Programa & 279 & 19,79 & 377 & 23,62 & 656 & 21,82 \\
\hline 010 & $\begin{array}{l}\text { Desempenho de funções pelos } \\
\text { alunos no Programa }\end{array}$ & 85 & 6,03 & 126 & 7,89 & 211 & 7,02 \\
\hline 011 & $\begin{array}{l}\text { Programa: um lugar para adquirir } \\
\text { conhecimentos }\end{array}$ & 62 & 4,40 & 149 & 9,34 & 211 & 7,02 \\
\hline 009 & Programa: Grande Rede Social & 98 & 6,95 & 97 & 6,08 & 195 & 6,49 \\
\hline 007 & Percepção dos cursos do Programa & 112 & 7,94 & 74 & 4,64 & 186 & 6,19 \\
\hline 003 & $\begin{array}{l}\text { Corpoe mente: fonte de } \\
\text { Juventude }\end{array}$ & 85 & 6,03 & 92 & 5,76 & 177 & 5,89 \\
\hline 002 & $\begin{array}{l}\text { Valoração VS preconceito à pessoa } \\
\text { Idosa }\end{array}$ & 93 & 6,60 & 69 & 4,32 & 162 & 5,39 \\
\hline 004 & Programas e sociedade & 80 & 5,67 & 80 & 5,01 & 160 & 5,32 \\
\hline 006 & Disciplinas cursadas no Programa & 73 & 5,18 & 85 & 5,33 & 158 & 5,26 \\
\hline 008 & $\begin{array}{l}\text { Percepção sobre os professores do } \\
\text { programa }\end{array}$ & 77 & 5,46 & 53 & 3,32 & 130 & 4,32 \\
\hline & Total & 1410 & 100,00 & 1596 & 100,00 & 3006 & 100,00 \\
\hline
\end{tabular}

Quadro 1. Frequência das UR's categorias semânticas entre pessoas idosas que participam do PIAM-UCR e da UnATI-UERJ. Rio de Janeiro, 2010.

A análise dessas categorias, permitiu constar que as representações sociais que as pessoas idosas construíram dos programas universitários para à terceira idade (UnATIs), estão intrinsecamente vinculadas a duas noções. A primeira está associada à tríade pessoa idosa-velhice e envelhecimento ${ }^{1}$ e a segunda à noção de universidade.

Conforme destaca Vergès (2005, p. 219) uma representação "pode não ser verdadeiramente autônoma, é em particular o caso dos objetos sociais novos que só se podem construir por referência a objetos mais antigos. Neste caso eles dependem de uma ou de várias outras representações". Noções que serão apresentadas a seguir.

\subsection{A UnATI e a pessoa idosa, a velhice e o envelhecimento}

Uma primeira noção que compõe a representação das UnATIs referese à ideia integral de pessoa idosa-velhice e envelhecimento. Trata-se de uma tríade inseparável para designar: o sujeito, a fase do ciclo vital, e o processo que vivem os seres humanos até a morte.

$\mathrm{Na}$ bibliografia referente a essas temáticas encontramos características que identificam cada uma delas, e que foram amplamente mencionadas pelos sujeitos nos depoimentos. Assim, 
diante das necessidades e desejos pessoais, nas dimensões biológicas, psicológicas e sociais, de cada um dos sujeitos analisados, encontramos que o ingresso e a participação constante nas UnATI são representadas com uma solução que, por diversas razões, permite satisfazer aqueles aspectos percebidos como problemáticos na velhice.

Para interpretar de maneira adequada estes elementos, sintetizou-se, na Figura 1, o contexto, os problemas percebidos e as soluções encontradas desde a perspectiva de cada sujeito, e que são satisfeitas por aquilo que as UnATIs representam para eles.

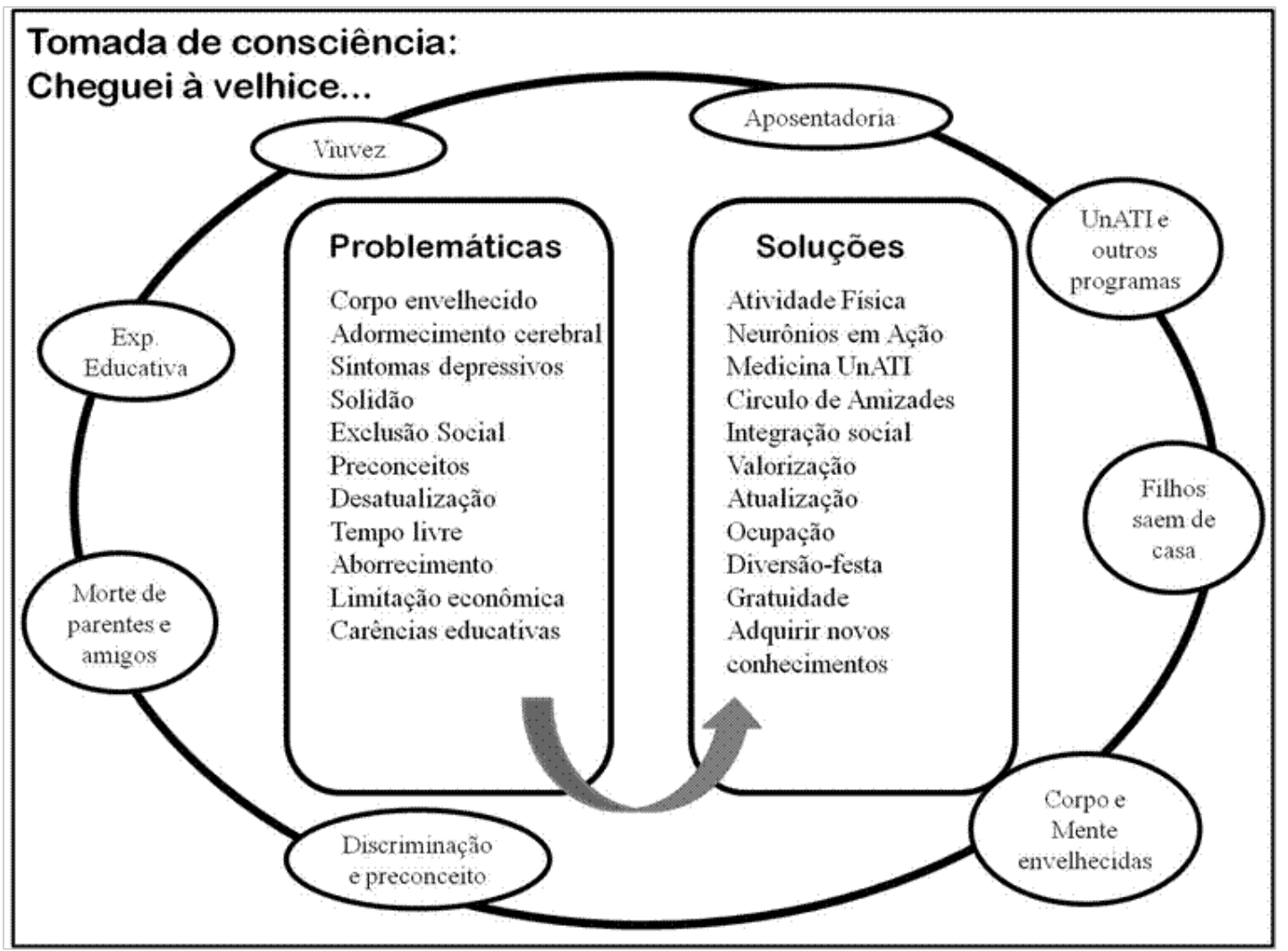

Figura 1. Esquema figurativo dos elementos de contexto prévios à inscrição nos programas analisados. Rio de Janeiro, 2010.

Cada elemento que compõe este esquema forma parte do material discursivo produzido pelas pessoas idosas. No marco externo encontramos o que os sujeitos chamaram de tomada de consciência: a velhice chegou.

Para Aranha (2007) passamos toda a nossa vida ignorando e negando o nosso próprio processo de envelhecimento. Envelhecer, indica a autora, não é "condicional somente à idade cronológica, mas sim a uma vivência subjetiva da passagem do tempo que, sendo subjetiva, depende da responsabilidade de cada um". Agrega ainda que "a velhice surge em nossas vidas como uma ruptura, denotando mudanças antes ignoradas, demonstrando vulnerabilidades e 
disfunções físicas e/ou psíquicas mais do que experiências e conquistas, que somente são percebidas posteriormente ao quadro inicial de espanto e de estranhamento - este geralmente comum no que se refere a minorias e a imagens estereotipadas, frutos de preconceitos instituídos culturalmente" (ARANHA, 2007, p. 255).

Como consequência da tomada de consciência da chegada da velhice, os sujeitos começam a pensar nos aspectos considerados como problemáticos nessa faixa etária, devido a sua forte valoração negativa. Os acontecimentos, às vezes simultâneos, surgem e constituem o contexto prévio que motiva as pessoas a procurar, dentre outras opções, inscrever-se numa UnATI.

Dentre os eventos que os sujeitos narraram (contidos nos círculos), e que são coerentes com o conhecimento reificado aparecem: a viuvez, a aposentadoria, a morte de parentes e amigos, a saída dos filhos de casa. Esses elementos, no contexto da velhice, são acompanhados pela experiência educativa ao longo da vida (que aparece como difícil, na maioria dos casos estudados), pela discriminação, pelo preconceito à velhice e por um corpo e uma mente percebidos como envelhecidos.

Diante destes acontecimentos, que podem resultar muito estressantes na velhice, os sujeitos destacam como elementos do contexto: (1) sentir que seu corpo estava envelhecendo; (2) seus neurônios estavam ficando adormecidos; (3) sintomas depressivos; (4) sentimento de solidão; (5) limitação na participação social; (6) sentiram-se alvo de preconceito e discriminação; (7) perceberem que seus conhecimentos estavam desatualizados; (8) perceberem que estavam com tempo livre disponível para realizar outras atividades; (9) percepção de inatividade e aborrecimento; (10) não procurarem outras atividades por condições econômicas e; (11) carências de tipo educativas que não foram satisfeitas em outras etapas da vida.

Nesse contexto, aparecem familiares, amigos, conhecidos, especialistas na área da saúde, entre outras pessoas (até chamadas de anjos), que recomendaram a inscrição no programa. Em poucos casos as pessoas souberam da existência dos programas pelos meios de comunicação de massa. Parte-se da premissa de que essas pessoas tiveram um papel fundamental na informação inicial que os sujeitos receberam sobre a UnATI, na medida em que a sua fala teve uma influência para que essa pessoa procurasse o programa e, consequentemente, realiza-se a inscrição.

É importante ressaltar que uma boa parcela dos sujeitos apresentou resistências em ambos os programas, por exemplo, a decisão de realizar ou não a inscrição por longos períodos, que chegou até 5 anos. Essas resistências falam sobre os medos e as incertezas frente a um objeto novo e desconhecido pelos sujeitos.

Com relação à transformação do não-familiar em familiar, um dos atributos principais da representação social, a propósito do processo 
de ancoragem, ou seja, aquele momento em que somos capazes de classificar e dar um nome às coisas que ainda não foram classificadas e que, portanto, resultam alheias, inexistentes e até ameaçadoras, destaca Moscovici (2003, p 61-62) que,

Nós experimentamos uma resistência, um distanciamento, quando não somos capazes de avaliar algo, de descrevê-lo a nós mesmos ou a outras pessoas. O primeiro passo para superar essa resistência, em direção à conciliação de um objeto ou pessoa, acontece quando nós somos capazes de colocar esse objeto ou pessoa em uma determinada categoria, de rotulá-lo com um nome conhecido. No momento em que nós podemos falar sobre algo, avaliá-lo então comunicá-lo mesmo vagamente, como quando nós dizemos de alguém que ele é "inibido" então nós podemos representar o não-usual em nosso mundo familiar, reproduzilo como uma réplica de um modelo familiar.

Toda vez que prevaleceu a curiosidade sobre a resistência, e foi estabelecido o contato inicial com o programa, as pessoas narraram uma satisfação com o mesmo na medida em que foram solucionadas aquelas problemáticas prévias à inscrição. Os participantes dizem sentir-se bem com a vida, estar realizados no plano pessoal, satisfeitos com os ganhos obtidos como consequência da sua participação no programa universitário e manifestam interesse em continuar inscritos até quando a vida permitir.

Essa satisfação configura as UnATIs como espaços que promovem a atividade física, colocam os neurônios para trabalhar, são uma cura/remédio para problemas psicoafetivos, promovem redes de amizade, valorizam a pessoa idosa, atualizam ou permitem adquirir conhecimentos, são gratuitos ou de baixo custo, são espaços de diversão, de festa, e que lhes permite manter-se ocupados.

Entre os elementos mencionados, aquele que recebeu maior destaque em relação ao nosso objeto refere-se às UnATIs como um espaço para compartilhar e fazer amizades. Entre as práticas de socialização percebidas pelas pessoas idosas, visualizam-se dois planos de cognição. O primeiro refere-se a todas aquelas práticas que são realizadas na cotidianidade dos sujeitos, no intercâmbio que acontece nas salas universitárias, no hall da universidade, no elevador, na cantina da universidade, entre outros espaços, os quais se apresentam no plano da realidade. O segundo diz respeito as práticas de socialização idealizada no horizonte de expectativas de futuro dos sujeitos, observando-se a expectativa de encontrar um parceiro ou a incerteza sobre quem serão os colegas no próximo semestre ou ano letivo.

Para Queiroz e Netto (2007) a sociabilidade e a educação são dois elementos responsáveis pela promoção do envelhecimento saudável e, como consequência, pela melhora da qualidade de vida. Para os 
autores um dos maiores problemas na velhice refere-se a solidão, fruto das perdas conjugais, de amigos e parentes, assim como da perda dos vínculos de trabalho com a aposentadoria. Os autores mencionam as UnATIs como um dos mecanismos para minimizar os efeitos da solidão, toda vez que promove o contato social e o desenvolvimento de novas capacidades de realização no âmbito pessoal.

Interessa ressaltar uma importante consideração que se aplica às UnATIs, considerando que este tipo de programa é formado por $80 \%$ de mulheres. Veras (2007) lembra o aumento significativo da expectativa de vida no grupo das mulheres, em relação ao grupo dos homens. O autor assinala que uma característica do grupo das mulheres é precisamente a solidão na velhice, solidão que representa uma experiência emocional intensa e estressante na cotidianidade das pessoas, que mobiliza a procura de novos contatos sociais. Por este motivo, não é casual que entre os principais componentes representacionais apareça a amizade.

Outro elemento que merece ser destacado pela sua presença majoritária no grupo da UnATI-UERJ, refere-se a esse "lócus" como espaço que promove a saúde, denominado em alguns casos de medicamento ou terapia. Para Neri (2008), o fenômeno da velhice é predominantemente feminino, na medida em que a expectativa de vida das mulheres é de 5 a 8 anos maior do que dos homens. No entanto, curiosamente as mulheres têm uma saúde mais precária do que os homens, sendo vítimas mais frequentes de doenças, como as encontradas nesta pesquisa, tais como: osteoporoses, diabetes, hipertensão e artrite.

A este respeito, Veras (2007) assinala que a universidade é a instituição pública que hoje em dia conta com maiores e melhores recursos para trabalhar com e para a população idosa. Neste sentido, a UnATI-UERJ oferece dentro da sua estrutura, assistência médica, jurídica e social, assim como diversas atividades de tipo cultural. Este discurso não entra em contradição com a percepção dos sujeitos que participam da UNATI/UERJ, na medida em que mencionam a existência destes recursos e dos benefícios para a saúde que eles percebem.

No caso do PIAM-UCR, a saúde é percebida apenas nos benefícios diretos das disciplinas cursadas sobre o seu corpo e a sua mente. $\mathrm{O}$ programa disponibiliza um seguro de saúde em coordenação com outra dependência universitária, a qual não tem relação direta com o programa, quiçá esta seja a causa de que o programa seja relacionado com a saúde unicamente a partir da experiência pessoal.

No entanto, evidencia-se a existência de um consenso em ambos os grupos, ao perceber que todas ou quase todas as pessoas que ingressam em uma UnATI têm um problema de saúde, e com o tempo e com a participação constante no programa, esses problemas 
começam a diminuir e até mesmo desaparecer, melhorando assim o seu estado físico de saúde, e como eles mesmos afirmam, até a aparência física muda.

\subsection{A UnATI como "universidade": porta de acesso ao conhecimento}

Associado ao elemento universidade emergem questões relativas à estrutura, organização e dinâmica institucional. Na literatura sobre o conceito de universidade é possível encontrar elementos compartilhados que operacionalizam o termo. A universidade constitui-se como uma instituição de ensino superior que abrange faculdades, confere níveis acadêmicos, compreende um prédio ou conjunto de prédios; tem um corpo docente e um discente, assim como um conjunto dos estudantes que dela participa.

A noção de universidade construída pelas pessoas idosas não escapa da noção da instituição em si, entendida no universo reificado. Os conhecimentos associados ao termo podem não compartilhar todos os seus elementos, mas certamente compartilham a questão do conhecimento. Neste sentido, observou-se que, o ponto de encontro entre ambos os grupos analisados se refere às UnATIs como espaços educativos, noção que se traduz em todas as facetas que a educação implica: informação, conhecimento, relação professor-aluno, disciplinas, entre outros. Neste sentido, não existem UnATIs sem a instituição superior de ensino, isto é, não existe uma universidade que não seja composta por uma estrutura que permita o acesso ao conhecimento.

O termo universidade conta com o reconhecimento social, na medida em que representa segurança, confiança e conforto. Por esses motivos, os sujeitos que realizaram a inscrição nas UnATIs referem elevar o seu conhecimento a um outro "status". No grupo da UnATIUERJ, os sujeitos referem ter "perfil universitário", que poderia entender-se como o acesso ao poder do conhecimento. Na prática, isso indica uma intenção de comunicar às pessoas que formam parte da sua cotidianidade que eles são estudantes da universidade, que estão saindo das suas casas para assistir a disciplinas universitárias, e que portam dentre seus documentos a carteirinha de estudante. Ou seja, objetivam na universidade a própria existência da UnATI.

Categorizar alguém ou alguma coisa, indica Moscovici (2003), significa escolher algum dos paradigmas contidos em nossa memória e estabelecer desta maneira uma relação positiva ou negativa com o objeto. Neste processo, as nossas classificações atravessam a comparação das pessoas com um protótipo, que geralmente é aceito como representante de uma classe, e que é o primeiro a ser definido através da aproximação, ou da coincidência com o último. Moscovici (2003, p. 64) indica que "nós estamos inclinados a perceber e a 
selecionar aquelas características que são mais representativas desse protótipo".

A partir dessa premissa, podemos encontrar uma classificação interessante com relação ao nosso objeto. $\mathrm{Na}$ sociedade atual sabemos que existem níveis educativos estabelecidos para cada faixa etária. Uma criança inicia seu percurso educativo na etapa préescolar passando posteriormente à escola, seguidamente ao colégio e finalmente à universidade.

No caso das UNATIS, existe uma necessidade de denominar esses programas de "universidades para idosos". No entanto, curiosamente nós não chamamos, por exemplo, o ensino fundamental de escola para crianças, o ensino médio de colégio para adolescentes, ou no caso do ensino superior, universidade para adultos.

No nosso entender e amparados na premissa de Moscovici (2003), essa situação acontece por dois motivos específicos. O primeiro diz respeito a impossibilidade de uma nomeação ou termo próprio do objeto sobre o qual estamos nós referindo, que o abranja na sua totalidade. O segundo aponta para a inexistência de um protótipo de referência em nosso cérebro que vincule a educação com as pessoas idosas. Por esses motivos, existe uma necessidade de buscar estabelecer uma relação com um termo já existente, como é o caso da universidade (valorizado positivamente), com outro termo (idoso, terceira idade) carregado de valorações negativas.

Observemos uma definição de UnATI que é compartilhada na literatura pertinente:

\footnotetext{
Universidade da terceira idade são programas de educação permanente de caráter universitário e multidisciplinar voltados à adultos maduros e idosos. Têm como pressuposto a noção de que a atividade promove a saúde, o bem-estar psicológico e social e a cidadania dessa clientela genericamente chamada de terceira idade. Os programas oferecem oportunidades para participação em atividades intelectuais, físicas, sociais, culturais, artísticas e de lazer (CACHIONI, 2008, p. 207).
}

Note-se que a percepção das pessoas sobre a UnATI e a percepção desta no saber técnico, em termos gerais, é congruente, evidenciando uma aproximação entre universos consensuais e reificados. Não existe aparentemente uma zona de conflito entre os dois planos teóricos apresentados, em ambos os programas. Por um lado a universidade tem uma função educativa, e por outro parte-se da premissa de que o idoso precisa melhorar sua qualidade de vida, sua saúde e o seu bem-estar.

No entanto, a análise de conteúdo que considerou os grupos estudados, constatou uma diferença significativa a respeito das formas de nomear as UnATIs. No caso da UnATI-UERJ os sujeitos se 
referem a ela como uma universidade propriamente dita, quer dizer, para eles a UnATI-UERJ é uma universidade aberta para a terceira idade, em todos os sentidos. Assim, ao mencionar o objeto eles falam "a nossa UnATI", evidenciando uma proximidade muito forte com o objeto.

No caso do PIAM-UCR os participantes a denominam como um programa da Universidade de Costa Rica (UCR) e não como uma universidade propriamente dita. Ao referir-se ao objeto, os sujeitos falam "a nossa UCR". Esse aspecto pode ser explicado a partir de dois motivos chaves: (1) o primeiro refere-se ao nome do PIAM, já que na sua composição não incorpora a palavra universidade e sim a palavra programa e; (2) em segundo lugar, o nome do programa sofreu variações desde a sua criação, mas nunca foi entendido como uma universidade e sim como uma parte da estrutura organizacional da UCR. Talvez a troca de nomes tenha influenciado os participantes a não se identificarem com o programa, e sim com a universidade, como instituição consolidada no país, da qual esse espaço faz parte.

Outros dois elementos que aparecem com contrastes distintos nos grupos são os docentes e as disciplinas vinculadas aos programas. Ambos os elementos não poderiam ser explicados sem antes entender a lógica que se oculta atrás do modelo que cada programa desenvolve. Em primeira instância, ambos os programas são o resultado do primeiro modelo proposto por Vellas em 1973, em sua versão modificada do Cambridge. Ambos compartilham o mesmo marco filosófico, qual seja, a educação permanente, e encontram-se vinculados à estrutura universitária na modalidade de projeto de extensão.

Partindo desse marco, cada programa adaptou o modelo segundo as suas necessidades e possibilidades de implementação, com significados distintos, mas com a mesma finalidade. Esse aspecto é amplamente discutido por Alfageme e Cabedo (2005). Os autores estabelecem as diferenças existentes entre programas universitários voltados à população idosa.

A principal diferença encontrada, na pesquisa, refere-se a que no PIAM-UCR as pessoas idosas participam com docentes universitários e com estudantes regulares em disciplinas que são oferecidas para a formação em nível do ensino superior e; como consequência esses docentes não contam necessariamente com uma capacitação em gerontologia ou em ciências afins.

Dentro do grupo da UnATI-UERJ, uma boa parcela dos sujeitos considera a qualidade dos professores muito boa a excelente. A preparação e a participação em atividades acadêmicas por parte dos docentes e discentes influem no trato percebido por parte das pessoas idosas. Esse discurso é encontrado na produção científica por parte do próprio coordenador da UnATI-UERJ, professor Veras (2007, p. 663), ao indicar que, 
Denize Cristina de Oliveira, Adriana Sancho Simoneau

A estruturação de micro universidades temáticas voltadas a terceira idade pode ser o ponto de partida. Nelas, os idosos recebem assistência e ensino e participam de atividades culturais e de lazer; além disso, propiciam uma coorte inestimável para pesquisas em várias áreas do conhecimento, ajudando, assim, na formação de profissionais de alta qualificação e alavancando a produção de conhecimento sobre a terceira idade.

No caso do PIAM-UCR, devido a sua estrutura organizacional, os docentes que lecionam no programa são, na sua maioria, voluntários. Em alguns casos, há aposentados que oferecem seus conhecimentos e tempo para disciplinas específicas do programa. Por este motivo, não são solicitados requisitos para ingressar como professor no programa. Outro tipo de professor é o docente de cada unidade acadêmica que, de forma voluntária, oferece vagas na sua disciplina ministrada a estudantes regulares para estudantes idosos. Em ambos os casos, os professores não estão capacitados para trabalhar especificamente com população idosa. Tal aspecto foi percebido por parte dos participantes desta pesquisa como negativo, na medida em que o trato interpessoal percebido não é adequado, consideram que os conteúdos das disciplinas não estão de acordo com as suas capacidades, nem com os seus interesses pessoais. Constatou-se que os professores fazem parte dos elementos que compõem a representação social das UnATIs, apesar de sua valoração ser distinta a partir da experiência de cada grupo.

Outro elemento mencionado refere-se às disciplinas como parte fundamental da estrutura que permite o acesso ao conhecimento. De maneira geral, em ambos os grupos foram percebidas valorações positivas com respeito à oferta das UnATIs. No entanto, no PIAM-UCR uma boa parte dos entrevistados referiu-se às disciplinas como difíceis ou pouco interessantes. Esta valoração foi estabelecida para as disciplinas que são oferecidas pelo programa na categoria disciplinas regulares. Estas disciplinas são oferecidas, na verdade, para estudantes jovens universitários, no entanto, conforme indicado os docentes oferecem vagas para incluir estudantes idosos em suas turmas. Neste sentido, considera-se que algumas das disciplinas regulares implicam em conhecimentos específicos prévios para serem cursadas, motivo pelo qual a pessoa idosa a cataloga como difícil ou pouco interessante.

A esse respeito, destaca-se aquilo que os participantes denominam como requisitos que devem ser solicitados para participar em uma UnATI e nas disciplinas oferecidas. Ambos os programas compartilham um único requisito de ingresso: a idade. No entanto, esse critério é distinto em ambos os grupos. No caso do PIAM-UCR a idade mínima é de 50 anos; e na UnATI-UERJ é de 60 anos. Em 
nenhum dos depoimentos foi referido outro requisito que as UnATIs poderiam eventualmente adotar para ingressar no programa. No caso do PIAM-UCR, os estudantes consideram que o programa deve solicitar requisitos de ingresso unicamente nas disciplinas regulares, de forma tal que a pessoa idosa não tenha dificuldades para cursá-la.

\section{Conclusão}

Os programas universitários para pessoas idosas vêm sendo cada vez mais reconhecidos como espaços educativos que promovem a qualidade de vida e o envelhecimento saudável das pessoas que se encontram nesta etapa do desenvolvimento humano. O modelo criado na França, com quase 40 anos de trajetória, com mudanças e adaptações ao longo desse tempo, foi acolhido praticamente em quase todos os países do mundo. O desenvolvimento da presente pesquisa permitiu acessar os conteúdos que caracterizam as representações sociais de pessoas próximas a este tipo de programas: as próprias pessoas idosas que participam nas UnATIs de dois países da América Latina: a Costa Rica e o Brasil.

Uma vez concluído o desenvolvimento deste trabalho, considerando a análise dos dados obtidos, foi possível tecer algumas interpretações a respeito dos elementos empíricos e teóricos encontrados nesta pesquisa.

Diante dos resultados descritos anteriormente, podemos concluir que o presente trabalho representa o início de um longo caminho a seguir para conhecer mais de perto as representações sociais, em seus conteúdos explícitos e implícitos que se escondem por trás dos elementos observados nesta pesquisa. Neste sentido, percebe-se a necessidade de aprofundamento no estudo das UnATIs como objeto e não como campus ou lócus de pesquisa.

$\mathrm{Na}$ análise empreendida constatou-se que a representação das pessoas idosas entrevistadas acerca dos programas universitários para a terceira idade está fundamentada no conhecimento reificado, com seu conteúdo associado à organização e práticas vinculadas à estrutura universitária, assim como com as características e representações vinculadas à pessoa idosa, à velhice e ao envelhecimento, conforme entendidas em nossa realidade LatinoAmericana.

Destaca-se um posicionamento positivo na representação das UnATIs como um lugar para compartilhar com pessoas da mesma idade num espaço de relacionamento social próprio para este grupo etário e como uma oportunidade para adquirir e renovar conhecimentos na velhice.

Compreendendo que as representações sociais guiam as práticas e as modificam, destaca-se a importância do presente estudo, que 
mostrou uma mudança significativa na concepção da velhice, não apenas com um enfoque biológico, mas com uma abordagem psicossocial marcante. Sem dúvida, as UnATIs mostram-se como objetos transformadores da realidade, na medida em que permitem às pessoas idosas repensar seu papel na sociedade e redimensionar a imagem do seu grupo nos seus contextos de pertença, a fim de romper com valorizações negativas e preconceitos sobre 0 envelhecimento e a velhice.

\section{Referências}

ALFAGEME, A.; CABEDO, S. Los programas universitarios para mayores. In: PINAZO, S.; SÁNCHEZ, M. (Orgs.). Gerontología. Actualización, Innovación y propuestas. Madrid: Pearson Educación, 2005, p. 367-389.

ARANHA, V. Aspectos Psicológicos do Envelhecimento. In: NETTO, M. (Org.). Tratado de Gerontologia. 2 ed. São Paulo: Atheneu, 2007, p. 255-265.

BARDIN, L. Análise de Conteúdo. Portugal: Edições 70, 2009.

CACHIONI, M. Universidade da Terceira Idade. In: NERI, A. (Org.). Palavras Chaves em Gerontologia. 3 ed. Campinas: Alínea, 2008, p. 207-210.

DUFRESNE. H. L'université du troisième âge (UTA). Reflets: revue d intervention sociale et communautaire, v. 2, n. 2, p. 144-149, 1996. Disponível em: <http://www.erudit.org/recherche/ref/>.

FRUTUOSO, D. A Terceira I dade na Universidade: relacionamento entre gerações no 3o milênio. Rio de Janeiro: Ágora da Ilha, 1999.

J ODELET, D. Representações Sociais: Um domínio em expansão. In: (Org.). As Representações Sociais. Rio de Janeiro: ẼUUERJ, 2001, p. 17-44.

MOSCOVICl, S. (Org.). Representações sociais: investigações em psicologia social. Petrópolis: Vozes, 2003.

NERI, A. (Org.). Palavras Chaves em Gerontologia. 3ạ Edição. Campinas, SP: Alínea, 2008.

Programa Integral para la Persona Adulta Mayor “Dr. Alfonso Trejos Willis" (PIAM). Catálogo de cursos. Universidad de Costa Rica. San J osé, Costa Rica: UCR, 2008.

QUEIROZ, Z.; NETTO, M. Envelhecimento Bem-sucedido: Aspectos biológicos, psicológicos e socioculturais. Importância da sociabilidade e da educação. In: __ . (Org.). Tratado de Gerontologia. 2 Ed. São Paulo: Atheneu, 2007, p. 807-815.

SÁ, C. A Construção do objeto de pesquisa em Representações Sociais. Rio de Janeiro: EdUERJ, 1998. 
VERAS, R. Atenção Preventiva ao Idoso: Uma abordagem de saúde coletiva. In: NETTO, M. (Org.). Tratado de Gerontologia. 2 Edição. São Paulo: Atheneus, 2007, p. 655-669.

VERAS, R.; CALDAS, C. UnATI-UERJ-10 anos. Um modelo de cuidado integral para a população que envelhece. Rio de J aneiro: Relume-Dumará/UnATI/UERJ, 2004.

VERGĖS, P. Os questionários para análise das Representações Sociais. In: MOREIRA, A; JESUINO, J. (Orgs.). Perspectivas teórico-metodológicas em Representações Sociais. J oão Pessoa: UFPB, 2005, p. 201-228.

\section{Endereço para correspondência Denize Cristina de Oliveira}

Universidade do Estado do Rio de Janeiro, Faculdade de Enfermagem, Bd. 28 de Setembro, 157, 7o. Andar, Vila Isabel, CEP 20551-030, Rio de Janeiro-RJ, Brasil Endereço eletrônico: dcouerj@gmail.com

\section{Adriana Sancho Simoneau}

Endereço eletrônico: adrineau2003@gmail.com

Universidade do Estado do Rio de Janeiro, Instituto de Psicologia. Rua São Francisco Xavier, 524/10 andar, sala 10.009, bloco F. CEP 20550-900. Maracanã, Rio de Janeiro RJ, Brasil.

Recebido em: 21/09/2010

Aceito para publicação em: 25/11/2010

Acompanhamento do processo editorial: Ana Maria Lopez Calvo de Feijoo

\section{Notas}

* Enfermeira, Doutora em Saúde Pública pela Universidade de São Paulo - USP e Pós-Doutora em Psicologia Social pela École des Hautes Etudes en Sciences Sociales (EHESS), Paris/França. Professora do Programa Pós-graduação em Psicologia Social da UERJ; Professora Titular da Área de Pesquisa na Faculdade de Enfermagem/UERJ, Rio de J aneiro, Brasil.

**Psicóloga; Mestre e doutoranda em Psicologia Social pelo Instituto de Psicologia da Universidade do Estado do Rio de Janeiro - UERJ. A pesquisa contou com uma bolsa da CAPES/CNPq-IEL Nacional-Brasil.

${ }^{1}$ No caso da UnATI-UERJ, as pessoas se referiam à pessoa idosa com a categoria Terceira Idade, conceito amplamente utilizado e ao mesmo tempo discutido no Brasil para designar este grupo etário. Já no caso da Costa Rica, a designação desta faixa etária é propriamente pessoa idosa ou em espanhol "persona mayor". Os termos velhice e envelhecimento foram utilizados em ambos os grupos. 